\title{
CORPO-ARTE: A PERFORMATIVIDADE EM FOCO
}

\author{
Cuerpo-arte: la performatividad en foco \\ The body-art: the performativity in focus
}

Gisela Reis Biancalana ${ }^{1}$

\begin{abstract}
Resumo
O presente texto tem como objetivo refletir sobre o corpo em estado de arte, trazendo a performatividade de Marina Abramovich como exemplo da discussão levantada. Portanto, o percurso metodológico adotado para alavancar a discussão proposta foi desenvolver um breve percurso histórico, apenas no sentido de situar a reflexão. Em seguida, coloca-se em discussão algumas abordagens atuais focadas no cuidado de si para, finalmente, trazer a Performance Arte e a artista Marina Abramovich como exemplo das proposições reflexivas levantadas.
\end{abstract}

Palavras-chave: Corpo; Arte; Performance

\section{Resumen}

El presente texto tiene como objetivo reflexionar sobre el cuerpo en estado de arte, trayendo la performatividad de Marina Abramovich como ejemplo de la discusión levantada. Por lo tanto, el recorrido metodológico adoptado para aprovechar la discusión propuesta fue desarrollar un breve recorrido histórico, apenas en el sentido de situar la reflexión. A continuación, se ponen en discusión algunos enfoques actuales dirigidos al cuidado de sí para, finalmente, traer el Performance Arte y la artista Marina Abramovich como ejemplo de las propuestas reflexivas levantadas.

Palabras clave: Cuerpo; Arte; Performance

\begin{abstract}
The present text aims to reflect on the body in state of art bringing the performativity of Marina Abramovich as an example of the discussion raised. Therefore, the methodological course adopted to leverage the proposed discussion was to develop a brief history, only in the sense of situating the reflection. Next, we discuss some current approaches focused on self-care to finally bring Performance Art and the artist Marina Abramovich as an example of the reflective propositions raised.
\end{abstract}

Keywords: Body; Art; Performance

\footnotetext{
1 Doutora em Artes pela UNICAMP. Entre os anos de 2014-2015 realizou pós-doutoramento na De Montfort University, Leicester, UK, investigando processos colaborativos de criação. Docente no Curso de Dança e membro permanente do Programa de Pós Graduação em Artes Visuais da Universidade Federal de Santa Maria. É líder do grupo de pesquisas Performances: arte e cultura, vinculado ao CNPQ, no qual investiga relações entre arte e universos socioculturais na criação de Performances Arte - e-mail: giselabiancalana@gmail.com
} 
Os incontáveis assuntos relacionados ao corpo, para além das artes, são alvo de investigações em diversos campos do saber como a antropologia, a sociologia, a psicologia, a filosofia, entre tantos, sob perspectivas também diversas. Muitas pesquisas na área de artes têm se voltado para o corpo como centro irradiador de seu fazer, principalmente atentando para as práticas corporais em seus diferentes contextos socioculturais. Vale ressaltar que, atualmente, estes contextos são atravessados no espaço-tempo uns pelos outros, revelando o campo expandido da arte contemporânea. Portanto, é fundamental ter em vista quais foram/são alguns pesquisadores que têm se debruçado sobre este tema, mesmo percebendo a impossibilidade de abarcar todos os desdobramentos advindos destes olhares múltiplos e dinâmicos.

Ao recortar este vasto campo de estudos, depara-se com alguns pensadores que têm chamado a prática artística corporal de cuidado de si. Entre eles, cabe citar o filósofo francês Michel Foucault e o filósofo japonês Yasuo Yuasa. No Brasil, Cassiano Quilici é um dos nomes que pesquisa sobre os estudos de si. Antes disso, Mauss (2011), Barba (1995), Strazzacappa (2006), Greiner (2005), são autores que atravessaram estas questões e que também merecem ser mencionados. Este exercício reflexivo objetiva abordar algumas destas questões trazendo à tona a Arte da Performance sob o prisma de algumas práticas adotadas pela artista performática Marina Abramovich. Para tal, foi desenvolvido um breve percurso histórico, apenas no sentido de situar a reflexão proposta. Em seguida, coloca-se em discussão a Arte da Performance e algumas abordagens atuais focadas no cuidado de si para, finalmente, trazer a artista Marina Abramovich como exemplo das proposições corporais levantadas.

A palavra corpo sempre foi acompanhada por um sentido ambíguo. Durante a Idade Média, na Europa cristã, a fragmentação entre corpo e alma regia o ser. O corpo já foi visto como materialidade profana nestas sociedades, nas quais valores religiosos ditavam as regras da existência humana. No Brasil, bem como em muitos outros lugares, a herança deste contexto sociocultural europeu, branco e colonizador, dominou muitas das práticas corporais desenvolvidas, seja por imposição ou por resistência a elas. Já na Idade Moderna (GREINER, 2005, p. 20), com o Renascimento, a razão vinha imperando soberana e, com o cientificismo cada vez mais operante, o corpo é visto como um objeto a ser estudado, primeiramente, através de um viés anatômico, fisiológico, enfim, vislumbrado a partir de suas qualidades biológicas desdobrando-se, posteriormente, nos estudos da psique. "Neste período há inquietações fundamentais como a necessidade de tornar visível o dentro do corpo e de entender melhor o fluxo de informações entre as partes do corpo e entre o corpo e o mundo" (GREINER, 2005, p. 20).

A imperiosa valorização iluminista da dimensão racional e pensante do ser humano reforça ainda mais, porém sob outra perspectiva, a fragmentação do corpo que passa a acentuar uma dualidade focada no corpo-mente. Contudo, na contemporaneidade, esta fragmentação está em cheque mesmo reconhecendo-se sua finalidade meramente metodológica. Porém,

como nem sempre a evidência científica consegue desarticular uma crença que ganhou muita estabilidade e se popularizou, a separação entre atividades que são entendidas como do corpo (bordar, andar de bicicleta, dançar, etc.) e as outras, atribuídas ao pensamento (estudar matemática, construir prédios, fazer discursos, etc.), ainda se mantém. (SALDANHA, 2009, p. 27)

No final do século XIX, inicia-se um processo de "libertar" o corpo de muitas convenções históricas. Entre elas, podese lembrar a intenção feminina de libertar o tronco dos espartilhos, liberando a imposição de uma forma acinturada tida como padrão de beleza, bem como de libertar a prisão do movimento e da respiração. Entre as manifestações artísticas que responderam fortemente a este intento está a dança. Desta maneira, estabelece-se o "início básico da dança, liberada de artifícios como sapatos de ponta, tutus ou temas fantásticos" (FARO, 1987, p 116). Cabe ressaltar aqui, que Isadora Duncan foi umas das primeiras bailarinas a abandonar o uso do espartilho, deixando o tronco livre destas amarras históricas.

Sendo assim, o corpo é afetado pelos questionamentos de seu período e olha para si evocando a razão e as forças da natureza, de certa forma para justificar a luta para livrar-se de amarras socioculturais impostas por setores dominantes. Todas essas modificações acompanhavam o pensamento cultural, político, filosófico, econômico e social da época e provocam o trabalho corporal dos artistas, redirecionando suas convenções em muitos aspectos. Daí para frente, aliadas ao desenvolvimento industrial e às novas tecnologias, multiplicaram-se as experiências perceptivas que fomentaram experimentações inéditas nas artes.

Do elevador às montanhas russas, passando pelo filme ou pela fotografia, as tecnologias da era industrial suscitam experiências perceptivas inéditas. Rupturas espaço-temporais, solavancos, acelerações induzem coordenações cinestésicas e novas modalidades de comportamento. (COURTINE E CORBIN, 2008, p. 525)

No mundo contemporâneo, ainda há reflexos destas maneiras de pensar o corpo. Entretanto, esta extrema valorização da dimensão pensante do ser humano começa a ser questionada em meados do século XX. Muitos artistas, ao logo do século XX, passaram a reformular o aprendizado adquirido em suas escolas anteriores ao reavaliarem os seus saberesfazeres sobre outros aspectos. A atitude de levar o corpo para ambientes outros, que não somente o museu ou o palco italiano, está entre as investidas dos artistas pós modernos já na segunda metade do século XX. Vários artistas também extravasaram as experimentações da gravidade em um constante diálogo do corpo com ela. Estas novas perspectivas 
afetam diretamente o trabalho corporal dos bailarinos como, por exemplo, nas performances Man Walking down the Side of a Building (1970) e Spiral, de Trisha Brown. Em ambos os trabalhos, há performers suspensos por cabos caminhando pelas paredes de um edifício.

Outras abordagens também se fazem latentes. Neste momento, ainda emergem pensamentos sobre hierarquias tradicionais nas quais um mestre consagrado determinava a proposição artística desde a concepção até a execução das obras. Neste momento, nos EUA, começam a surgir os coletivos que sustentavam uma atuação compartilhada dos seus papéis no grupo. $O$ tempo e a imobilidade também são focos de reflexão. A imobilidade aparente também é considerada movimento, a "escuta dos ritmos fisiológicos desempenha nesta perspectiva um papel preponderante [...]. O silêncio e a imobilidade são as condições primeiras dessa atenção nova aos rumores do ser". (CORBIN E COURTINE, 2008, p. 519). Os assuntos abordados pelos artistas também passam a assumir questões conceituais da própria arte, sem representar, sem contar histórias, sem inspirar-se em elementos externos a si mesma.

Entre as concepções de corpo recorrentes, uma das expressões usadas mais conhecidas, e que evidencia o pensamento ambíguo supracitado, traz anteriormente a palavra corpo unida a um pronome que indica posse. O pronome meu, "meu corpo", ainda é recorrente nos discursos que recaem sobre alguns questionamentos. Será que o ser humano possui um corpo como se ele fosse uma entidade externa a ele? A mente e/ou a alma seriam externos ao ser e o corpo seria um objeto ou um recipiente a ser preenchido? No entanto, além do pronome "meu" intensificar esta separação, de acordo com Novaes e Vilhena, o próprio significado da palavra corpo se encaminha para esta dupla direção de sentidos, pois se

seguirmos o curso das significações que ele evoca, a palavra "corpo" faz pensar, ao mesmo tempo, na vida e na morte. Com efeito, o "corpo" pode designar o cadáver, como sugere sua etimologia. O substantivo corpo vem do latim corpus, corporis, que designa o corpo morto, o cadáver, a charneira, por oposição a alma (anima). Em grego clássico, essa significação seria parcialmente expressa pelo termo soma, que designaria, em termos gerais, o corporal por oposição ao incorporal, ou seja, o corpo como passível de apodrecimento, dissolução etc. (NOVAES, VILHENA, 2016, p. 233)

Entretanto, se a cultura ocidental, de origem europeia dominante e colonizadora, como afirmado acima, estabeleceu e reverberou esta separação, é claro entender como ela se faz amplamente presente ao longo da história. Cabe ressaltar que muitas concepções de corpo orientais percorreram caminhos diferentes. No Japão e na China, por exemplo, o corpo "já era entendido a partir dos seus diferentes estados, sendo sempre ativo e nunca considerado como um instrumento ou objeto" (GREINER, 2005, p. 22).

Para Foucault, a "relação de corpo e cuidado de si envolve o corpo em uma unidade corpo-alma, que precisa ser compreendido de um modo integral, pois um elemento está inteiramente conectado com o outro" (BOLSONI, 2012, p. 9). A relação corpo-mente atrelada às práticas corporais é colocada pelo filosófo japonês Yasua Yuasa como uma das maneiras de (re)integrar este ser. Yuasa (apud GREINER, 2005, p. 22) parte da suposição de que"a relação corpo-mente muda através do treinamento do corpo, o que se processa pela cultura e a formação (keikô) propriamente dita". Desse modo, Greiner traz a experiência do/no corpo como um dos caminhos para compreender as relações conflituosas das concepções históricas dos termos corpo e mente. Assim, é

apenas depois de adotar este ponto de partida experiencial que se pode perguntar qual é a relação entre corpo e mente. Ou seja, este debate nunca pode ser restrito a uma especulação exclusivamente teórica. Ele se origina em uma experiência prática, vivida (taiken) que implica num continuum mente-corpo em um sujeito e em seus trâmites com o ambiente. (GREINER, 2005, p. 23)

Refletir sobre estas transformações, bem como sobre o modo que elas alteraram o fazer artístico no mundo contemporâneo, traz implicações na maneira com a qual os artistas se relacionam consigo mesmos e com os outros. Os corpos-arte que, talvez, tenham iniciado esta jornada com o objetivo de ganhar visibilidade de si em processo ou até mesmo outros buscando mais atenção para si em meio ao competitivo e espetacularizado mundo contemporâneo, agora estão voltandose para ativar um ser-estar-sentir-agir de-por-consigo, no-com-pelo mundo.

Neste contexto, os métodos, sistemas, técnicas, modos de cuidar de si são frutos do espaço-tempo e das culturas às quais os indivíduos e as sociedades pertencem. A procura por ir pela contramão da instantaneidade do mundo contemporâneo, ouvir-se, escutar o outro, experimentar as sensações que emanam dos saberes que se instauraram no próprio corpo, são tarefas recorrentes àqueles que se propõe ser-estar-fazer arte. Tudo isso é corpo, que vem se organizando dinamicamente no dia-a-dia para vislumbrar e atingir seu estado de arte. Portanto, a busca por repensar dinamicamente estes encaminhamentos de si gera reformulações a partir de um entendimento de corpo calcado no respeito e na escuta de si mesmo antes de tudo.

Ao pensar sobre todos esses encaminhamentos possíveis, relacionados às práticas e, especialmente a este cuidado de si, surgem inquietações relacionadas a sua formalização. Um dos primeiros autores a refletir sobre as práticas corporais em diversas culturas foi o sociólogo e antropólogo francês Marcel Mauss. Mauss (2011), de modo geral, já mencionava que as práticas corporais cotidianas são condicionadas. Na esteira deste pensamento, emerge a questão que toca o exercício diário entendido como maneira de "instrumentalizar" o corpo. Por outro lado, se a busca por práticas corpo- 
rais para atingir um estado de arte está na escuta e no respeito, ou seja, são práticas que buscam não ser utilitárias e funcionais, a instrumentalização seria uma forma de adestramento da qual procura-se escapar e ao mesmo tempo parece constituir um percurso próprio do conhecer-se. Diante deste paradoxo, relações de poder também são levadas em conta. Segundo Bolsoni, tanto

o cuidado exagerado quanto o conhecimento ilimitado do corpo podem produzir a sua instrumentalização. Se o cuidado demasiado o coloca em situação de evidência e o instrumentaliza, o conhecimento sobre o corpo se concretiza sob sua instrumentalização, pois a maior proporção desse conhecimento estabeleceuse nas relações de poder exercidas sobre ele, na disciplina imposta aos corpos. Portanto, as dificuldades enfrentadas hoje estão vinculadas no poder enraizado sobre o corpo. (BOLSONI, 2012, p. 12)

Entretanto, apesar de ser difícil a tarefa de ir contra a esta cristalização instrumentalizadora e adestrativa das práticas corporais, se "o sujeito conseguir olhar por um viés diferenciado, por um olhar próprio e autônomo e buscar sua constituição de forma singular, passa a não ser estimulado pelos ideais exteriores". (BOLSONI, 2012, p. 13). Neste momento, é fundamental atentar para a singularização das proposições voltadas para trabalhos corporais. A questão não é "não ser estimulado pelos ideais exteriores", mas, sim, perceber de que maneira eles são reconhecidos e o que é possível fazer com eles, a partir do momento em que eles são absorvidos pela singularidade de cada um.

Técnica, método, treinamento, cuidado de si, entre outros, são termos que vêm sendo utilizados para referir-se ao trabalho corporal de artistas performativos. Como denominar os trabalhos realizados, atualmente, com o objetivo de cuidar de um corpo que é arte? Este cuidado é imprescindível? Como ressituar o fragmento em busca de certa organicidade psicofísica para a vida e para a Performance? Essas maneiras de referir-se ao trabalho corporal dos artistas performativos abre espaço para uma série de questionamentos que advêm de suas diferentes abordagens. Aqui, torna-se imperiosa a tentativa escorregadia de situar algumas destas indagações sem a pretensão de esgotá-las, tarefa árdua para um pequeno artigo, tendo em vista as amplas e complexas discussões em curso.

Sendo assim, o que seria técnica? Segundo o dicionário de língua portuguesa Scotini (2009), técnica seria "a arte de fazer algo, conhecimento científico e prática de execução; conjunto de conhecimentos intelectuais e práticos profissionais". Esta concepção calcada, sobretudo, no significado usual, funcional e cotidiano da palavra, leva ao entendimento de que ela constitui saberes e fazeres construídos para fins específicos. São saberes-fazeres que obedecem a regras e normas provenientes de tradições em transmissão. Portanto, neste contexto, seriam saberes-fazeres que existem independente do corpo que as realiza. Para Mauss, a técnica "precisa ser tradicional e eficaz. Não há técnica e não há transmissão se não houver tradição" (MAUSS, 2011, p. 407). Após observar a movimentação dos corpos por diversas partes do mundo, e a partir desta noção de técnicas do corpo, classificou-as através de divisões e variações de acordo com o sexo, a idade, o rendimento e sua transmissão/ensino. O autor concluiu, então, que todas as ações do homem são técnicas adquiridas. "Em suma, talvez não exista maneira natural no adulto" (MAUSS, 2011, p. 405). Esta colocação, no mínimo, discorre sobre o homem como ser cultural e que as tradições se inscrevem nos corpos pela própria ação humana. Por outro lado, a cultura é viva nos seres que as produzem, portanto, esta inserção cultural das tradições é dinâmica porque está amparada por escolhas, determina-se por circunstâncias ao mesmo tempo que é imbuída de desejos.

Atualmente, "a pluralidade de técnicas corporais é consequência da pluralidade de corpos. Não há uma técnica única que possa servir a todos os corpos, nem um corpo que possa se adaptar a todas as técnicas." (MORANDI, STRAZZACAPPA, 2006, p. 45). De modo geral, estas técnicas têm uma raiz comum na cultura europeia que colonizou as Américas e outros cantos do mundo, deixando marcas fortes e dominantes nas terras conquistadas. Portanto, vale considerar que, atualmente, existem técnicas provenientes de outras culturas, espaços e tempos, que têm sido absorvidas nos universos artísticos contemporâneos, também como tantas outras e novas possibilidades expressivo-comunicativas, carregadas de potencial criador tanto quanto qualquer outra. O importante, aqui, é destacar que os saberes provenientes das técnicas só fazem sentido a partir de sua materialização em laboratórios de experimentação artística, respeitando e ouvindo necessidades e desejos individuais. As técnicas fazem sentido quando corporificadas em um indivíduo que manifesta sua singularidade, constituindo-se como corpo-arte atuante.

Barba (1995), por sua vez, apresenta uma definição sobre técnica voltada especificamente para fins artísticos. Para ele, há dois tipos de abordagem técnica: a técnica voltada para fins objetivos e funcionais do cotidiano, e a técnica extracotidiana, voltada para performatividade, entre elas as performances artísticas. Para o autor e diretor teatral italiano, ambas são sustentadas por encaminhamentos socioculturais, mas as técnicas cotidianas surgem de um esforço para solucionar questões utilitárias do dia a dia, como a locomoção e a alimentação, por exemplo. Já as técnicas extracotidianas seriam aquelas que necessitam de um trabalho específico a ser adquirido com fins expressivos. Estas técnicas desenvolvem habilidades ao corpo performativo para movimentar-se de maneiras não realizadas diariamente. Entretanto, em relação a estas definições, surgem críticas. Uma delas remete-se a esta separação entre técnicas cotidianas e técnicas extracotidianas. 
Para Barba, quando o ator está em representação, sua técnica corporal muda radicalmente, não estando mais sob a influência dos condicionamentos da sua cultura. No entanto, um acrobata, por exemplo, é sempre um acrobata, seja no circo, seja fazendo suas compras. O indivíduo é um só. O corpo, com sua cultura, sua técnica, seus símbolos, constitui uma unidade. Uma vez a técnica adquirida, ela lhe pertence. Ele não pode utiliza-la ao fazer suas compras, mas ela estará sempre lá com ele, como as impressões digitais. (MORANDI, STRAZZACAPPA, 2006, p. 44).

Sendo assim, para as autoras supracitadas, as técnicas instauradas corporalmente estão presentes no cotidiano e em cena, mesmo que de maneira quase invisível. Não há como desmembrar a técnica do corpo, ou vice-versa. Paralelamente às discussões sobre técnica, pode-se pensar, ainda, questões sobre os métodos. Método é definido por Helena Katz como "um conjunto de instruções mais abertas, mais gerais" (KATZ, 2009, p. 28) e é voltado para determinados modos de fazer com que os conhecimentos sejam aplicados. Eles são fundamentados por pressupostos investigativos. A partir deste ponto de vista, ela observa como a separação entre técnica e método surge como consequência da divisão entre o fazer e o pensar. Ou seja, fruto da dualidade corpo e mente supracitada.

Segundo Courtine (2008, p. 199), a palavra treinamento, por sua vez, surge dos ambientes de tratamento de cavalos e foi adaptada para outros universos. De acordo com o autor, a palavra treinamento "durante muito tempo foi reservada ao trabalho de preparação dos cavalos de corrida". Porém, com o decorrer dos anos, a palavra foi emprestada devido a sua aplicabilidade a outros instâncias e campos de conhecimento. Neste percurso, houve uma reavaliação no sentido do termo que poderia ser também pensado como preparação ou consciência corporal. Estas abordagens mais individualizadas parecem dirigir-se ao que vem sendo chamado de cuidado de si. Assim, atualmente, o entendimento original passa de um simples apelo ao virtuoso em direção "a um objetivo mais profundo, mais complexo, o de um interminável e íntimo desabrochar pessoal" (COURTINE, 2008, p. 198). Ainda segundo Courtine, a

mudança mais importante ainda é aquela que se refere aos efeitos esperados do treinamento e do desenvolvimento físico: uma psicologia de conquista levou a se imaginar descobertas intimas. O trabalho sobre si, a prospecção de "mensagens internas", a exploração do sensível transformaram amplamente, nas décadas recentes, as vias do exercício como também muitos de seus desafios. Além do esporte, com ele, paralelamente a ele, o "treinamento" se tornou um mundo, um recurso especialmente particular onde se pensa que o sujeito ganha mais do que antes em domínio, mas também em elucidação de si mesmo, se não um pleno desabrochar pessoal. (COURTINE, 2008, p. 221)

O contexto que abarca o trabalho corporal de artistas recai sobre muitas linguagens. Porém, o que interessa aqui é a Arte da Performance. Discutir Performance é um tema que por si só pressupõe uma gama enorme de práticas artísticas, já que as investidas em delimitar um conceito são amplas, abarcando diversas outras linguagens em suas tentativas de definição. Isto remete às origens mais recentes dessa linguagem no início do século XX, ligada às Vanguardas e que conquista sua autonomia entre as décadas de sessenta e setenta. A Performance surge deste contexto no qual pensava-se na hibridação de linguagens, uma comunhão que também pressupunha eliminar as artes do artificialismo e do ilusionismo (GLUSBERG, 1987), para assim, surgir o que é uma de suas definições principais: o corpo do artista emerge na obra, tornando-se a própria obra ou, nas palavras de Battcock (apud COHEN, 2002, p.76), o artista é "a própria arte".

No entanto, por apresentar essa amplitude tentacular e que engloba artistas provenientes de diversas linguagens, consequentemente, acaba por produzir obras distintas que se reúnem em torno deste conceito dilatado de Performance. A intenção de tornar o corpo a própria obra pressupõe inúmeras formas de trabalhar com esse recurso discursivo. Além disso, faz pensar se adotar um modo de trabalho corporal diário do artista se faz realmente necessário.

Muitos artistas não têm nenhum trabalho corporal voltado para a performatividade. Grande parte deles são artistas visuais que não são formados em uma tradição calcada nas artes corporais. Os artistas provenientes do teatro e da dança já precisam deste trabalho diário de si mesmos. Na Performance, há diferentes modos de trabalhar corporalmente que podem estar intimamente ligados à linguagem de formação de cada performer, de seu contexto sociocultural, de sua relação com a arte, entre tantas outras influências. Assim, o tratamento dado ao corpo pelo artista que trabalha com Performance se distingue de outro que trabalha com desenho, escultura, pintura, entre outros. Este trabalho também vai se distinguir do trabalho realizado por atores ou bailarinos. Mesmo entre os performers, eles trabalharão (ou não) diferentemente sobre tais questões.

Entretanto, artistas como Marina Abramovic (2018), lutam para a legitimação da Performance, buscando torná-la não uma arte alternativa, mas, sim, uma nova proposição que se baste em si mesma. Em seu percurso de vida, realizando Performances há mais de quatro décadas, a artista sérvia de 72 anos de idade, adotou seu modo de ser este corpo-arte. Ao perceber os diferentes modos de ser na vida e na arte de performar, ou de estar em Performance, a artista costuma afirmar em suas entrevistas que busca uma experiência de si para que seu público possa também ter sua própria experiência. Assim, o acontecimento seria uma experiência ${ }^{2}$ compartilhada entre performer e público.

2 A acepção desta palavra no sentido dado por Bondía (2002, p. 21): “Poderíamos dizer, de início, que a experiência é, em espanhol, 'o que nos passa'. Em português se diria que a experiência é 'o que nos acontece'; em francês a experiência seria 'ce que nous arrive' (...)". Em Heidegger (1987) podemos encon- 
Entretanto, atingir os sentidos do público, provocar transformação, tocar o interior de quem o vê, propor uma experiência diferenciada do cotidiano, são proposições que não são intrínsecas ao conceito de Performance. Colocar-se enquanto corpo em Performance não quer dizer, automaticamente, que o público será atingido sensivelmente. Presenciar e experienciar uma Performance não significam a mesma coisa. Para Bondía (2002, p. 22), a experiência deve ser separada da informação, pois o saber da experiência é diferente do saber coisas. A informação não toca necessariamente, ela pode ser apenas uma leitura de algo que produz conhecimento racional sobre as coisas do mundo. Este saber é diferente da leitura sensível, não exclusivamente racional, que pode propor uma experiência mais profunda. Ao falar sobre Performance, Cohen propõe

a eliminação de um discurso mais racional e a utilização mais elaborada de signos [que] fazem com que o espetáculo de performance tenha uma leitura que é antes de tudo uma leitura emocional. Muitas vezes o espectador não "entende" (porque a emissão é cifrada), mas "sente" o que está acontecendo. (COHEN, 2002, p.66)

As escolhas de Abramovic vêm de um profundo conhecimento de si. Extremamente espiritualizada, ela tem seguido o budismo tibetano em busca do silêncio, da filosofia e do autoconhecimento. Mesmo que ela não se relacione diretamente com os conceitos abordados, é possível observar aproximações entre seu percurso e as discussões voltadas para o cuidado de si. Portanto, para ativar esse corpo da-na-pela Performance, um corpo que provoque uma experiência para além do puro racionalismo cotidiano, alguns performers trabalham primeiramente a si mesmos. A experiência acontece primeiramente no próprio artista para que ele possa abrir um canal de relação com seu público, como faz Abramovic. A artista pretende propor experiências a si mesma e ao seu público. Suas obras exigem muito de seu preparo corporal para conseguir o objetivo desse contato consigo mesma para relacionar-se com o público.

Uma de suas obras performáticas recente, muito simples e extremamente desafiadora, foi The Artist is Present. Nesta Performance, ela propõe ficar sentada no The Modern Art Museum durante oito horas por dia, seis dias por semana, num período de três meses, esperando pessoas sentarem para lhe olhar. Esta proposta exige dela um preparo intenso.

De sua entrevista, destacam-se dois aspectos de seu trabalho que se aproximam da discussão levantada. Primeiro, a sua necessidade de investimento em um trabalho corporal que acompanha sua vida. Este trabalho exige um controle psicofísico que advém de seus meios de preparação focados no contato consigo mesma. De acordo com a própria artista, ela utiliza métodos da meditação budista para atingir esse controle necessário para atingir objetivos como o da Performance citada. O segundo aspecto é um entendimento de preparação e Performance como experiência modificadora do ser, não somente na arte, mas na vida. A obra afeta não apenas o público, mas, principalmente, o próprio artista. Ambos são sujeitos desta passagem, espaço-tempo de relação essencial para a experiência. Para Bondía o sujeito da experiência

não é o sujeito da informação, da opinião, do trabalho, que não é o sujeito do saber, do julgar, do fazer, do poder, do querer. Se escutamos em espanhol, nessa língua em que a experiência é 'o que nos passa', o sujeito da experiência seria algo como um território de passagem, algo como uma superfície sensível que aquilo que acontece afeta de algum modo, produz alguns afetos, inscreve algumas marcas, deixa alguns vestígios, alguns efeitos (BONDIA, 2002, p.19)

O que seria o público destas proposições performáticas senão um território de passagem. Para essa interferência mútua se consumar para além do mero olhar/apreciar, pode-se recorrer, ainda, a Didi-Huberman (1997), quando o autor fala sobre o que se vê e o que nos olha. O olhar que aquilo que Didi-Huberman requisite não é apenas aquele que é visível materialmente na forma da obra. Para ele, deve-se ir além desta materialidade. Ao mesmo tempo em que se olha para uma obra, algo acontece no trânsito entre o público e ela. Ao olhar para os objetos artísticos com todas as referências pessoais, a obra parece olhar para o público trazendo todas as suas referências. Tal exemplo, embora aplicado à relação do público com objetos artísticos, poderia ser transposto para a Arte da Performace. Didi-Huberman propõe que os objetos têm algo a refletir e, quando se refere ao corpo do performer, seria possível estender tal pensamento para além do objeto-obra. $\mathrm{O}$ autor ressalta que é preciso fechar os olhos para ver realmente. Isso pertence ao campo da experiência ao se deixar impregnar pela obra. De acordo com ele, o

ato de ver não é o ato de uma máquina de perceber o real enquanto composto de evidências tautológicas. O ato de dar a ver não é o ato de dar evidências visíveis a pares de olhos que se apoderam unilateralmente do 'dom visual' para se satisfazer unilateralmente com ele. Dar a ver é sempre inquietar o ver, em seu ato, em seu sujeito. Ver é sempre uma operação de sujeito, portanto uma operação fendida, inquieta, agitada, aberta. Entre aquele que olha e aquilo que é olhado (DIDI-HUBERMAN, 1998, p.77).

trar uma definição semelhante: "Hacer una experiencia con algo - sea una cosa, un ser humano, un dios - significa que algo nos acaece, nos alcanza; que se apodera de nosotros, que nos tumba y nos transforma. Cuando hablamos de «hacer» una experiencia, esto no significa precisamente que nosotros la hagamos acaecer; hacer significa aquí: sufrir, padecer, tomar lo que nos alcanza receptivamente, aceptar, en la medida en que nos sometemos a ello. Algo se hace, adviene, tiene lugar" (HEIDEGGER, 1987). 
Deste ponto de vista, o ambiente relacional que se estabelece entre performer e público se aproxima da experiência dita por Bondía. Em obras como as de Abramovic, esta relação propõe uma experiência compartilhada que, para a artista, necessita de um preparo de si para ser vivenciada. Ela refere-se diretamente à transformação pessoal, em primeira instância, e de seu público. Entretanto, essa transformação, esse tocar o outro ainda podem ser termos vagos que nada definem o trabalho da artista, ou que poderiam soar confuso. Tal aspecto estaria ligado diretamente ao tipo de comunicação que ela busca com seu público, uma "transmissão direta de energia entre o artista e o público" (QUILLICl, 2008, p. 2). Para essa conexão ocorrer depende de um árduo trabalho sobre si mesmo. A comunicação que Abramovic busca não pertence ao campo da racionalidade e da informação, mas, sim, da experiência. A experiência, por sua vez, não reside em qualquer qualidade de presença ou a qualquer experimento aleatório. Suas Performances não ocorrem apenas no plano da informação e da decodificação dos códigos que propõe. Suas Performances vão além, tocam os sentidos em duas vias, pela relação que se estabelece com seu público.

\section{Referências}

BARBA, Eugenio; SAVARESE; Nicola. A arte secreta do ator: dicionário de antropologia teatral. São Paulo: Hucitec; Campinas: Unicamp, 1995.

BONDÍA, Jorge Larrosa. "Notas sobre a experiência e o saber de experiência”. Revista Brasileira de Educação, n. 19, p. 20-28, Rio de Janeiro, jan./abr., 2002.

COHEN, Renato. Performance como linguagem. São Paulo: Ed. Perspectiva/USP, 2002.

CORBIN, Alain; COURTINE, Jean Jacques; VIGARELLO, Georges. História do corpo. Vol. 3: As mutações do olhar: O Século XX. Petrópolis: Vozes, 2008.

DIDI-HUBERMANN, Georges. O que vemos, o que nos olha. São Paulo: Editora 34, 1998.

FARO, Antônio José. Pequena história da dança. Rio de Janeiro: Jorge Zahar, 7. edição, 2011.

GLUSBERG, Jorge. A arte da performance. São Paulo: Ed. Perspectiva, 1998.

GREINER, Christine. "O corpo do artista: as publicações mais recentes e suas redes interdisciplinares", Salvador/BA,

Repertório Teatro \& Dança, ano 4, n. 5, 2001.

GREINER, Cristine. O corpo: pistas para estudos indisciplinares. São Paulo: Annablume, 2005.

MAUSS, Marcel. Sociologia e antropologia. São Paulo: Cosac e Naify, 2011.

MORANDI, Carla; STRAZZACAPPA, Márcia. Entre a arte e a docência. Campinas: Papirus, 2006.

NOVAES, V.; Joana; VILHENA, Junia. Que corpo é este que anda sempre comigo? Curitiba: Appris, 2016.

SALDANHA, Suzana. Angel Vianna: sistema, método ou técnica? Rio de Janeiro: FUNARTE, 2009.

STRAZZACAPPA, Márcia. "As técnicas corporais e a cena". Etnocenologia: textos selecionados (orgs.) Christine Greiner e Armindo Bião. São Paulo: Annablume Editora, 1998.

BOLSONI, Betania Vicensi. O cuidado de si e o corpo em Michel Foucault: perspectivas para uma educação corporal não instrumentalizadora. Disponível em: <http://www.ucs.br/etc/conferencias/index.php/anpedsul/9anpedsul/ paper/viewFile/1577/920>. Acesso em: 2012.

HEIDEGGER, M. De camino al habla. Barcelona: Serbal, 1987. Disponível em: <http://www.heideggeriana.com.ar/textos/ esencia habla.htm>.

ABRAMOVIC, Marina. Entrevista. Disponível em: <https://www.youtube.com/watch?v=|9rdqoFLOZE>. Acesso em: 2018. 
QUILICI, Cassiano Sydow. O Treinamento do Ator/performer e a "Inquietude de Si". CONGRESSO DA ABRACE, 5, 28 a 31 de out., 2008. Disponível em: <http://www.portalabrace.org/vcongresso/textos/territorios>. Acesso em: 2013. 